\title{
Estimation of Errors in Calculated Liquid Rocket Injector Performance Using a Miniature Cryogenic Test Stand
}

\author{
By Brunno B. VASQUES ${ }^{1)}$ and Oskar J. HAIDN ${ }^{1)}$ \\ ${ }^{1)}$ Institute of Space Propulsion, Technical University of Munich, Garching b. München, Germany
}

(Received June 22nd, 2017)

\begin{abstract}
Liquid oxygen and liquid methane rocket engines are leading candidates for a variety of space missions, including the critical role of main descent propulsion of planetary landing spacecraft. Particular mission characteristics in this context may dictate the use of propulsion systems with deep-throttling capability and able to deliver good performance over the entire thrust range. A well-known injector type with favourable combustion stability, heat transfer and performance characteristics is the pintle injector. This atomizer has been tested with a variety of propellants, such as monomethyl hydrazine/nitrogen tetroxide, fluorine/methane and oxygen/hydrogen. However, characterization employing liquid oxygen and liquid methane is relatively scarce. In order to obtain relevant parametric performance data at nominal and off-nominal conditions, a miniature cryogenic test stand operating with $\mathrm{LO}_{2} / \mathrm{LCH}_{4}$ propellants was designed and built. Presented here are the results of a systematic study to determine the uncertainty of measured and calculated parameters defining pintle injector performance. The approach used for the measurement of relevant quantities such as thrust, propellant flow rates, temperature and pressures is discussed and a description of the methodology used in the error analysis is given. Final values of uncertainty in characteristic velocity efficiency are presented for different pintle injector configurations.
\end{abstract}

Key Words: Cryogenic Test Stand, Oxygen/Methane Propellants, Pintle Injector, Rocket Performance Estimation.

\section{Nomenclature}

$\begin{array}{cll}A & : & \text { area, }\left[L^{2}\right] \\ B & : & \text { bias error } \\ C_{d} & : & \text { discharge coefficient, }[-] \\ C^{*} & : & \text { characteristic velocity, }\left[L T^{-1}\right] \\ C_{F} & : & \text { thrust coefficient, }[-] \\ d & : & \text { diameter, }[L] \\ f & : & \text { correction factor (pressure), }[-] \\ F & : & \text { force, }\left[M L T^{-2}\right] \\ h & : & \text { specific enthalpy, }\left[L^{2} T^{-2}\right] \\ K_{m} & : & \text { global mixture ratio, }[-] \\ L^{*} & : & \text { chamber characteristic length, }[L] \\ \dot{m} & : & \text { mass flow rate, }\left[M L^{-1}\right] \\ N & : & \text { number of samples } \\ p & : & \text { pressure, }\left[M L^{-1} T^{-2}\right] \\ S & : & \text { specific entropy, }\left[L^{2} T^{-2} K\right] \\ S & : & \text { precision index } \\ t & : & \text { t-Student's parameter } \\ T & : & \text { temperature, }[K] \\ U & : & \text { uncertainty } \\ V & : & \text { velocity, }\left[L T^{-1}\right] \\ X & : & \text { parameter in a sample } \\ \beta & : & \text { correction factor, }[-] \\ \Delta & : & \text { differential } \\ \epsilon & : & \text { contraction ratio, }[-] \\ \eta & : & \text { efficiency, }[-] \\ \theta & : & \text { influence coefficient } \\ \kappa & : & \text { thermodynamic property } \\ v & : & \text { degrees of freedom } \\ \rho & : & \text { density, }\left[M L^{-3}\right] \\ \phi & : & \text { correction factor, }[-] \\ & & \end{array}$

$\begin{array}{cll}\text { Subscripts } & & \\ 95 & : & 95^{\text {th }} \text { percentile point of t-Student's } \\ & & \text { distribution } \\ D I S & : & \text { ambient } \\ D I V & : & \text { discharge } \\ e & : & \text { divergence } \\ \text { eff } & : & \text { exfective } \\ \text { exp } & : & \text { experimental } \\ f & : & \text { fuel } \\ F R & : & \text { friction } \\ H L & : & \text { heat loss } \\ i & : & i^{\text {th }} \text { parameter or measurement } \\ \text { inj } & : & \text { injector } \\ \text { idealinj } & : & \text { idealized injector } \\ k & : & \text { chamber } \\ K E & : & \text { chemical kinetics } \\ \text { line } & : & \text { propellant line } \\ o & : & \text { oxidizer or stagnation } \\ p & : & \text { pressure factor } \\ t & : & \text { throat } \\ T & : & \text { total } \\ \text { th } & : & \text { venturi throat } \\ \text { theo } & : & \text { theoretical } \\ T R & : & \text { throat radius } \\ \text { vac } & : & \text { vacuum } \\ & \end{array}$

\section{Introduction}

Investigation of liquid rocket engines with variable thrust capability have been pursued since the late 1930s. ${ }^{2}$ The ability to modulate the engine thrust has been a necessity in a variety of mission profiles: 
- During orbit manoeuvres including orientation and stabilization;

- In space rendezvous and docking;

- For hovering and landing on the surface of celestial bodies;

- In ballistic missile trajectory control.

Throttling ranges are mission dependent; higher ratios are used when a more precise trajectory control is needed. Ratios bellow 4:1 (i.e. $25 \%$ of rated thrust level) are usually considered "shallow throttle", requiring simpler techniques for propellant regulation. With respect to propellant combination, mission analysis for planetary landing applications has indicated a need for propulsion systems with high specific impulse and low-toxicity. Liquid oxygen and liquid methane are currently leading candidates for these applications. Compared to liquid hydrogen, liquid methane provides a higher bulk density in combination with liquid oxygen and can be readily stored in space, due to its higher boiling point. Theoretical peak performance is achieved at a mixture ratio of 3.5 at an expansion area ratio of $400: 1$. $^{1)}$ However, before these advantages can be realized in an actual lander propulsion system, two facts must be considered. First, knowledge of the processes involved in the atomization and mixing of propellants in the combustion chamber throughout the throttling range is necessary to obtain optimum performance and stability, ${ }^{3)}{ }^{4)}$ Secondly, among all hydrocarbon fuels, methane possesses the lowest heat capacity as a liquid. As a result, regenerative cooling can only be effected at pressures above the critical pressure (ca. 45.8 [MPa] for methane), where problems of boiling heat transfer can be avoided. Therefore, unless propellant tanks can be built light enough to withstand such pressure levels, the use of a complex pump-fed propellant delivery system has to be considered. For a lander application, where reliability and reaction time are of paramount importance, this decision must be carefully evaluated. Depending on mission profile, passively cooled thrust chambers can be envisioned as a feasible alternative to regeneratively cooled chambers. Since the injector plays a major role in defining overall propulsion system performance, stability and chamber-wall heat transfer characteristics, the need existed to evaluate the performance of liquid oxygen and liquid methane propellants in combination with injection systems which possess some degree of throttling potential. For this purpose, a fully mobile, miniature, cryogenic test bench was conceived, designed and built. While the concept privileged flexibility and small size, the referred test stand design incorporates solutions common to large scale test facilities. In order to assess injector performance with an adequate degree of confidence, knowledge of errors in calculated performance parameters is fundamental. General literature related to uncertainty analysis are found in Refs. 9) and 10), with a particular application for a gaseous oxygen-gaseous hydrogen rocket engine provided by Ref.11). The objective of the present study is to establish an uncertainty methodology and to assess the corresponding errors on the values of characteristic velocity and combustion efficiency obtained from hot-fire tests using the cryogenic test bench conceived and employing four different pintle injector configurations.

\section{Experimental Apparatus}

\subsection{Calorimetric combustion chamber}

For evaluation of the injector types and screening of potential design configurations, short-duration firings using an uncooled combustion chamber and nozzle were performed. The nominal design parameters were a throat diameter of $13.5[\mathrm{~mm}]$ and a contraction ratio of 13 with characteristic chamber lengths $L^{*}$ between 1.45 and $2.40[\mathrm{~m}]$. Such a large contraction ratio was based upon a previous conceptual study which indicated that sufficient surface area must be available for heat pick-up, if a regenerative cooling scheme is envisioned. The nominal mixture ratio of 2.8 is the result of a trade-off between theoretical performance and fuel availability to serve as a coolant. Chamber pressures of 0.5 to $1.5[\mathrm{MPa}$ ] were adopted in the early investigations and explore the range typical to pressure-fed thruster applications.

\subsection{Injector selection}

The pintle injector was the initial candidate selected because of its performance potential and development flexibility, permitting a large number of systematic variations in injection parameters within the same basic hardware. This type of atomizer is unique in that a single moving sleeve can control the gaps accurately to maintain the proper absolute and relative injection stream velocities over the throttling range. For flight-type throttling propulsion systems, the injector is not required to be a flow mechanism; it can be linked to control valves which assume this function, and thus the injector can be adjusted for optimum combustion efficiency, ${ }^{5)}$. ${ }^{\text {) }}$

Some key design parameters pertaining pintle injector design include: ${ }^{7)}$

- Injection stream physical size and shape;

- Individual stream kinetic energy;

- Momentum- and velocity-ratio between interacting streams;

- Spray angles;

- Wall compatibility;

- Mass flux distribution and injection pattern across chamber cross-sectional area.

At the outset of the design phase, a goal was established to evolve a configuration which would incorporate maximum flexibility as well as economy in fabrication. The final injector design is a building block version with replaceable injection elements, permitting rapid modifications with minimum effort, see Fig. 1.

In this particular design, thrust level variation is achieved in the single-point firings by adjusting the thickness of spacers defining fuel flow gap and by replacing oxidizer orifice sizes.

\subsubsection{Overview of pintle injector design}

Hydraulic design of the pintle injector is fundamentally based upon obtaining a mechanical interlock of the propellants which forces liquid phase mixing to occur. For the present investigation, the oxidizer is employed as the center propellant, being metered and directed radially outward as individual streams from the central pintle. The fuel, therefore, is injected as a hollow cylindrical sheet which intercepts the oxidizer streams, with part of the fuel impinging the oxidizer and part of it penetrating between the oxidizer orifices. The parameters which showed a 


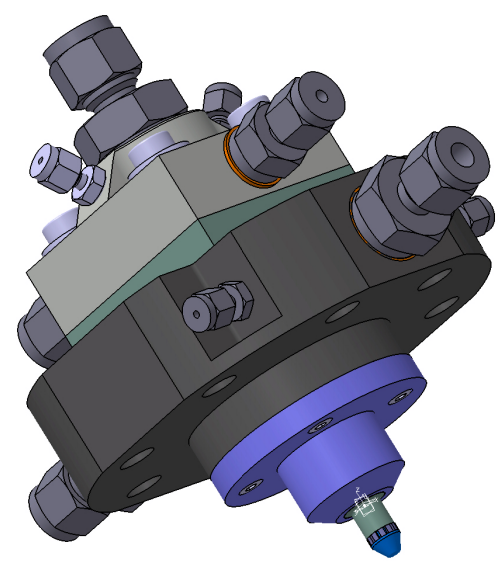

Fig. 1. 3-D view of pintle injector.

dominating influence on injector performance ${ }^{7)}$ are as follows:

1. Ratio of oxidizer-to-fuel injection momentum;

2. Ratio of secondary oxidizer flow to primary orifice flow;

3. Number, size and shape of central orifices;

4. Elemental spacing of central orifices;

5. Length between annular flow injection point and point of impact with the central radial streams;

Variation of these parameters are used to control both performance and wall environment. As a part of the design analysis, the effects of geometry, momentum and velocity ratios, impingement angles and pressure drops were then studied. The results of these analyses were used to establish all of the injector dimensions. By considering initially the continuity equation and liquid injection at an average temperature of $120[\mathrm{~K}]$ and the flow area-pressure relationship we obtain:

$$
C_{d} A=\left[\frac{\dot{m}}{2 \rho \Delta P}\right]^{1 / 2}
$$

where $C_{d}$ is the average injector discharge coefficient, $A$ is the flow area, $\dot{m}$ is the propellant mass flow rate and $\Delta P$ is the pressure drop across the element. It is found from Eq. (1) that the propellant injection area requirements are small for a 500-[N] class thruster. However, the area is a function of the orifice pressure drops selected, and this parameter must be controled and matched with the oxidizer pressure drop for mixing performance. A simple but effective approach to this control is obtained through an examination of the gross dynamics of interaction of fuel and oxidizer. The factor involving momentum ratios is a measure of the inherent propellant energy for atomization and mixing. From first principles, this ratio is represented as: ${ }^{8)}$

$$
\frac{F_{f}}{F_{o}}=\frac{\dot{m}_{f} V_{f}}{\dot{m}_{o} V_{o}}
$$

It becomes then evident that to assure peak performance can occur virtually through all throttling range, it is necessary to optimize the injector hydraulics. The criteria usually established for pintle injectors is applicable in either case of sheet or jet injectors. This criteria implies that sheet types of one-on-one elements should perform best for: ${ }^{7)}$

$$
\left(\frac{\rho_{o} V_{o}^{2}}{\rho_{f} V_{f}^{2}}\right)\left(\frac{d_{o}}{d_{f}}\right)=1,
$$

or in terms of mixture ratio:

$$
K_{m}^{2} \frac{\rho_{f}}{\rho_{o}}\left(\frac{d_{f}}{d_{o}}\right)^{3}=1 .
$$

On the basis of the foregoing design approach, it was finally established that the optimum velocity ratio for $\mathrm{LO}_{2} / \mathrm{LCH}_{4}$ at the design mixture ratio of 2.8 is approximately:

$$
\frac{V_{o}}{V_{f}}=\frac{1}{\left(\dot{m}_{o} / \dot{m}_{f}\right)}=0.35 \text {. }
$$

\subsection{Ignition system}

In the present investigation a torch and a resonance igniter were initially considered. However, for reasons of simplicity and relatively high reliability, a conventional torch igniter running on gaseous oxygen and gaseous methane was designed and employed throughout the test-firings. Nominal chamber pressure was $0.35[\mathrm{MPa}]$ at a mixture ratio of 2.5. Igniter operating times varied slightly during the tests. An average 0.600 [ms] operating time proved sufficient for the majority of main engine mixture ratios investigated.

\section{Cryogenic Test Stand}

All hot-firing test activities were conducted at the rocket test facility of the Faculty of Space Propulsion in Garching, Germany. An overall view of the completed cryogenic test stand is shown in Fig. 2. Due to laboratory space limitations, the test stand was conceived as a movable, flexible unit; each propellant feed-system is mounted on a fold-out table that can be directly aligned to the injection head connection points. The various test stand systems are discussed in the following sections.

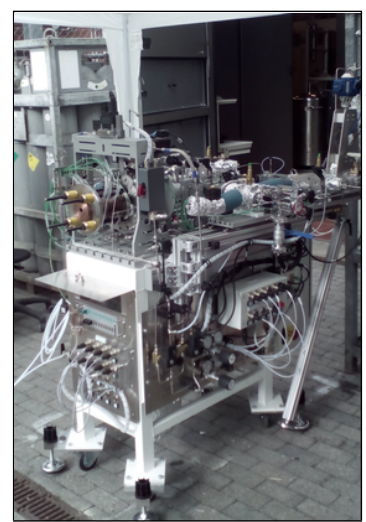

(a) Test stand roll-out.

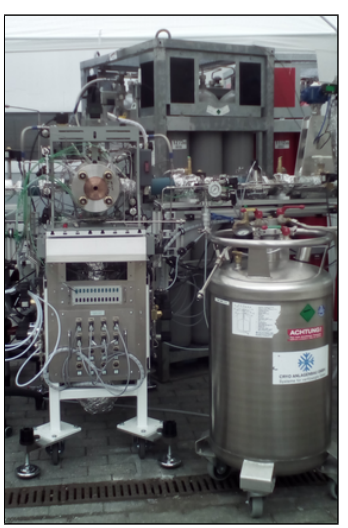

(b) Feed-system preparation.

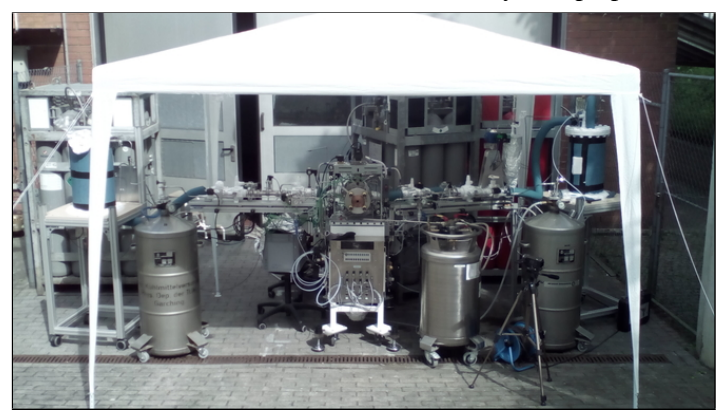

(c) Typical test setup.

Fig. 2. Overall view of the miniature cryogenic test stand. 


\subsection{Liquid methane supply system}

Production of liquid methane took place prior to testing and employed a pressurized liquid nitrogen bath at $0.65[\mathrm{MPa}]$ to keep methane temperature within the liquid range. A regulated supply of gaseous methane flowed through a stainless steel tubing coil built around a cylindrical storage tank immersed in the liquid nitrogen bath. This tank was pressurized to a level of $0.2[\mathrm{MPa}]$ for propellant tranfer operations. The actual outlet temperature of liquid methane was around $120[\mathrm{~K}]$. A second, 3-liter "run tank", was used for supplying sufficient liquid methane for the firing. The $\mathrm{LCH}_{4}$ produced in the liquefier was made to circulate in the propellant lines and venturi meter through a series of isolation and bypass valves, before reaching the run tank. A liquid nitrogen refrigerant flow supplied by a 100-liter dewar was maintained throughout the test for cooldown operations. Propellant lines upstream and downstream of the instrumentation unit were simply foam insulated. This was especially important in order to reduce line stiffness and attenuate thrust cell side-loading effects. The line segment containing the venturi meter was vacuum insulated. Thermal control of the methane line proved difficult due to the low mass flows involved and the high heat input from ambient. The $\mathrm{LN}_{2}$ refrigerant flowrate was then adjusted to result in methane temperatures upstream of the venturi meter as low as 120 [K]. In general, the overall methane flow system was broken down into a number of parallel flow circuits, rather than flowing all sections in a single series arrangement. A bypass of flow (bleed) was provided that tapped-off the $\mathrm{LCH}_{4}$ propellant supply system. The bypass control valve was automatically sequenced off just prior to the actuation of the main fuel valve. Pressurization of the run tank was made directly by gaseous methane by switching the corresponding pressurizing valve. An electro-pneumatically driven valve isolated all the flow system from the engine in the event of a sequence failure. Gas supply to this valve and to all fuel line purge operations was made with a dedicated gaseous nitrogen provision.

\subsection{Liquid oxygen supply system}

Liquid oxygen was produced on-site by direct liquefaction of gaseous oxygen flowing through a coil immersed in a liquid nitrogen bath. The coil was made out of stainless steel tubing spun around a 3-liter capacity tank. This tank was completely immersed in the liquid nitrogen bath and stored the liquefied oxygen produced for the firing. It was possible, by selective actuation of isolation valves, to flow $\mathrm{LN}_{2}$ through both the $\mathrm{LO}_{2}$ supply system and the line jackets for preliminary system cooldown or temperature control. The liquid oxygen supply system from the tank to the main valve was a vacuum-insulated, $\mathrm{LN}_{2}$-jacketed line. As in the case of the $\mathrm{LCH}_{4}$ system, a liquid nitrogen refrigerant flow was maintained through the jacket passages in the instrumentation unit and a final run of approximately $30[\mathrm{~cm}]$ line leading to the engine was unjacketed. This segment was simply foam-insulated during chilldown. This was adopted for simplicity and to increase thrust measurement accuracy. The $\mathrm{LN}_{2}$ refrigerant flowrate was controlled by varying the dewar supply pressure, allowing delivery of liquid oxygen to the $\mathrm{LO}_{2}$ venturi meter at temperatures as low as $85[\mathrm{~K}]$. A bypass flow system was provided which tapped off the $\mathrm{LO}_{2}$ propellant supply system immediately downstream of the venturi meter. The bypass control valve maintained a continous flow through that portion of the system until just prior to actuation of the engine main oxidizer valves. The bypass valve shut-off and opening of the oxidizer main valve were controlled by the sequencer. A dedicated gaseous nitrogen system was used for all line purges. The oxidizer tank pressurization was provided by the gaseous oxygen entering the liquefier, through actuation of pressurizing valves.

\subsection{Igniter supply system}

Regulated supplies of $\mathrm{GO}_{2}$ and $\mathrm{GCH}_{4}$ ran through stainless steel tubing mounted along each folding table and connected via flexible hoses to the respective igniter valves. Correct igniter mixture ratio was achieved by metering both flows through sonic orifices mounted downstream of each valve. Spark energy was provided by a $10-\mathrm{kV}$ electric spark coil generator. A regulated supply of $\mathrm{GN}_{2}$ was used for igniter purge and cleaning procedures during checkout operations.

\subsection{Chamber installation details}

Details of the chamber installation may be seen in Fig. 3. The thrust absorbing structure was a frame made of $10-[\mathrm{mm}]$ thick steel plates welded together. This structure provided enough seismic mass and damping. Two steel flexures, located 90 degrees apart, were used to permit axial motion of the engine, while supporting the weight of the hardware and absorbing side loads. The engine was bolted to a thrust mount that threaded into the body of the load cell. This mount had a conical shape that was partially relieved to provide access to the thrust calibration fixture. The fixture consisted of a ball-bearing mounted, right-angled lever system which allowed hanging weights on the horizontal arm.

\subsubsection{Instrumentation and controls}

The pressure transducers used were mainly thin-film strain gage instruments and where oxygen compatibility and superior corrosion resistance was required, ceramic strain gage transducers were adopted. The load-cell used for thrust measurements was a bonded strain-type transducer with a $1000[\mathrm{~N}]$ rating. This load-cell was selected to provide a high-stiffness and, thus, to result in a high thrust mesasurement response. The cryogenic range temperature measurements were made with copper/constantan (propellant tanks) and chromel/alumel (feed-system) thermocouples by use of feed-throughs or standard connectors. Elevated temperatures, such as those exhibited by the chamber surfaces during firing, were monitored with iron/constantan thermocouples. These were of the bare wire type with stripped leads for faster response. Innerwall, transient temperature data, used $0.5[\mathrm{~mm}]$-diameter probe chromel/alumel thermocouples. These thermocouples were pressed against the bottom of the mounting holes with an average force of ca. $3.5[\mathrm{~N}]$, ensuring proper contact of the thermocouple sensing tip with the chamber inner-wall at all times. The propellant flowrates were measured using subcritical venturi meters specially designed for this purpose. A three-wall stainless-steel construction was conceived to permit a continuous flow of $\mathrm{LN}_{2}$ through the inner annular passage, while a vacuum was maintained in the outer annulus for superior thermal insulation. Upstream and downstream of the venturi meters, two mounting blocks were attached. These fully instrumented blocks served as a manifold for the $\mathrm{LN}_{2}$ refrigerant flow and 


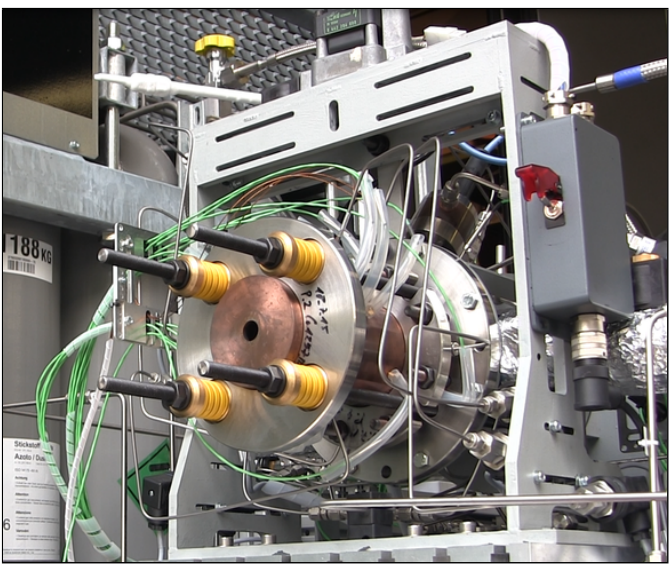

(a) Front view

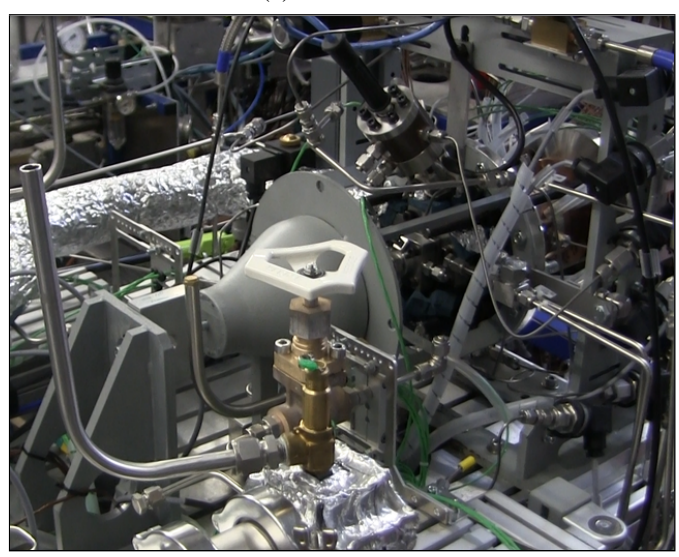

(b) Rear view.

Fig. 3. Chamber installation with provisions for pressure, temperature and force measurements.

provided interface to all bypass, relief, isolation and main engine valves. A 3-D conceptual schematic and a photograph of the complete instrumentation unit is shown in Fig. 4a and Fig. $4 \mathrm{~b}$, respectively. Valve actuation as well as chamber start- and shut-down logics were implemented in conjunction with a Programmable Logic Controller (PLC). Manual and automatic actuation modes could be executed by selecting the appropriate switch position. A manual abort switch that could override any previous logic inputs was available to the operator. Any firing could also be automatically aborted by any of the redline input signals. Dedicated card modules were used for data acquisition at $160[\mathrm{ksamples} / \mathrm{s}]$ and 14 bit resolution.

\section{Data Reduction Procedures}

\subsection{Combustion efficiency computation}

The index of injector performance used in this study was the corrected combustion efficiency. The correction is necessary inasmuch as it isolates the effects of mixing and vaporization, the two factors of more relevance in injector performance evaluation. By assuming initially a perfect injector, the efficiency attributed to a particular injector design will be:

$$
\eta_{C^{*}}=\frac{C_{e x p}^{*}}{C_{\text {idealinj }}^{*}} .
$$

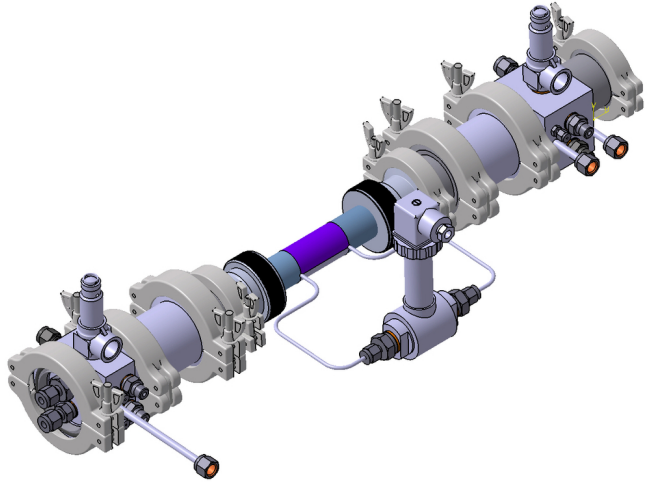

(a) 3-D view of the instrumentation unit.

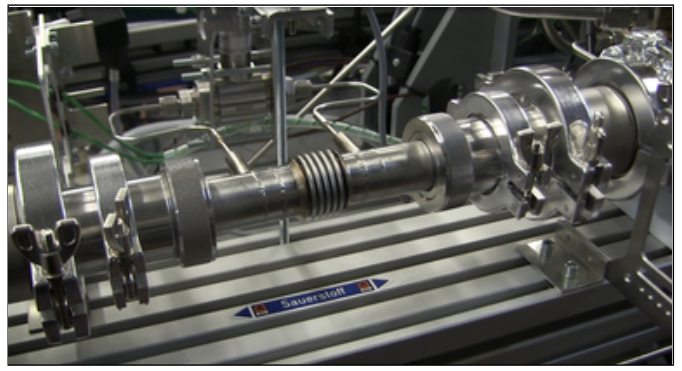

(b) Detail of venturi meter installation.

Fig. 4. View of three-wall venturi meter and mounting blocks.

where $C_{\text {idealinj }}^{*}$ is the characteristic velocity that would be obtained with a perfect injector. This value equals the theoretical equilibrium characteristic velocity corrected for effects of throat geometry, chemical kinetics, boundary layer and chamber heat losses.

Two independent methods were used for calculating $C_{\text {exp }}^{*}$, one based on measurement of chamber pressure and the other on measurement of thrust.

\subsubsection{Chamber pressure method}

Characteristic velocity efficiency based on chamber pressure is defined by the following:

$$
\eta_{C^{*}}=\frac{\left(p_{k}\right)_{o}\left(A_{t}\right)_{e f f}}{\dot{m}_{T} C_{\text {theo }}^{*}} .
$$

As mentioned previously, values obtained via Eq. (7) are referred to as corrected characteristic velocity efficiencies, because the factors involved are obtained by application of suitable influence factor corrections to measured quantities. Stagnation pressure at the throat is obtained from measured static pressure at start of nozzle convergence by assumption of isentropic expansion and effective throat area is estimated from measured geometric area and from geometrical radius changes during firing and for non-unity nozzle discharge coefficient. Chamber pressure can be corrected to allow for energy losses from combustion gases to the chamber wall by heat transfer and friction. Eq. (7) may therefore be written as follows:

$$
\eta_{C^{*}}=\frac{p_{k} A_{t} f_{p} f_{T R} f_{D I S} f_{F R} f_{H L} f_{K E}}{\left(\dot{m}_{o}+\dot{m}_{f}\right) C_{\text {theo }}^{*}} .
$$




\subsubsection{Calculations based on thrust}

The alternate determination of characteristic velocity efficiency is based on thrust:

$$
\eta_{C^{*}}=\frac{F_{v a c}}{\dot{m}_{T}\left(C_{F}\right)_{v a c} C_{\text {theo }}^{*}} .
$$

Values of vacuum thrust are obtained by correcting the sealevel measurements. These corrected values can then be used in conjunction with theoretical thrust coefficients for calculation of $C^{*}$. Nozzle efficiency is taken as $100 \%$ if there is no combustion in the nozzle, if chemical equilibrium is maintained in the expansion process and if energy losses from the combustion gases are taken into account. ${ }^{9)}$

$$
\eta_{C^{*}}=\frac{\left(F+p_{a} A_{e}\right) \phi_{F R} \phi_{D I V} \phi_{H L} \phi_{K E}}{\left(\dot{m}_{o}+\dot{m}_{f}\right)\left(C_{F}\right)_{\text {theo }} C_{\text {theo }}^{*}} .
$$

In Eq. (10), the correction factors are directly applied to vacuum thrust rather than the measured thrust, because, for convenience, the factors are readily calculated as changes in efficiency based on theoretical vacuum parameters. Implicit in the use of theoretical $C_{F}$ values are corrections to geometric throat area and to measured static chamber pressure at the start of nozzle convergence. Therefore, calculation of corrected $C^{*}$ efficiency from thrust measurement includes all factors of Eq. (10) plus an additional one to account for non-parallel nozzle exit flow. Because $\left(C_{F}\right)_{\text {theo }}$ is essentially independent of small changes to chamber pressure and contraction ratio which are involved in corrections to $p_{k}$ and $A_{t}$, these corrections are of no practical significance in calculation of $C^{*}$ from thrust measurements. Methods of estimation of the various correction factors are described in Ref. 9).

\subsection{Mass flow rate computation}

Experimentally, both methods of combustion efficiency computation require knowledge of the mass flow rate of propellants. This parameter is obtained by considering venturi meter upstream pressure and temperature conditions and by calculating the corresponding flow velocity at the venturi throat:

$$
V_{\text {th }}=\sqrt{\frac{2\left(h_{\text {line }}-h_{\text {th }}\right)}{\left[1-\left(\frac{\rho_{\text {th }}}{\rho_{\text {line }}}\right)^{2} \beta^{4}\right]}} .
$$

In this case, pressure at the venturi throat must be known:

$$
p_{\text {th }}=p_{\text {line }}-\Delta p \text {. }
$$

The propellant thermodynamic state points at the venturi throat are obtained by assuming isentropic flow to the throat, i.e.

$$
s_{\text {th }}=s_{\text {line }} .
$$

In Eq. (11), the parameter $\beta$ is the line contraction ratio, defined by:

$$
\beta=\frac{d_{t h}}{d_{\text {line }}} .
$$

The mass flow across any of the venturi meters can be calculated as follows:

$$
\dot{m}=C_{d} A_{t h} \rho_{t h} V_{t h}
$$

where $C_{d}$ is the venturi discharge coefficient obtained from water flow calibrations.
Finally, the total propellant flow is given by

$$
\dot{m}_{T}=\dot{m}_{o}+\dot{m}_{f}
$$

\section{Uncertainty Analysis Description}

The parameter used in this study for characterization of error in a given measurement is the uncertainty $U$, made up of bias $B$ and precision $S$. Precision is the variation between repeated measurements and the standard deviation of this group of data points characterizes the random error. For samples cointaining more than 30 data points the error range can be generally regarded as twice the computed standard deviation and includes $95 \%$ of the total spread of measurements. ${ }^{9)}$ Depending on the characteristics of the measurement or group of data, different approaches may be used to calculate $S .{ }^{11)}$ In a very general way, the precision index $S$ is given by:

$$
S_{X}=\sqrt{\frac{\sum_{i=1}^{N}\left(X_{i}-\bar{X}\right)^{2}}{N-1}} .
$$

Bias represents the constant or systematic error. In repeated measurements, it is assumed that each data point has the same bias. Whereas precision can be estimated based on calibration and test history, unknown bias factors need to be estimated. Alternatively, the known components of bias can be eliminated by comparison with the true value.

Sources of bias and precision error are assumed in this study to result from calibration, data acquisition and data reduction procedures. The root sum square method is used to combine these numerous sources of error. As a result, for the bias,

$$
B=\sqrt{B_{1}^{2}+B_{2}^{2}+B_{3}^{2} \ldots+B_{N}^{2}}
$$

where $B_{i}$ is the systematic error of the $i^{\text {th }}$ elemental source.

In a similar way, for the precision index:

$$
S=\sqrt{S_{1}^{2}+S_{2}^{2}+S_{3}^{2} \ldots+S_{N}^{2}}
$$

where $S_{i}$ represents the precision index of the $i^{\text {th }}$ error source involved.

A single number describing both factors and having a simple interpretation is highly desirable. The uncertainty interval is the most widely used standard:

$$
U^{ \pm}=B^{ \pm} \pm t S
$$

In other words, $U$ represents the interval within which the true value is expected to lie, given a certain confidence level or coverage. In this study, a confidence level of $95 \%$ was considered:

$$
U_{95}^{ \pm}=B^{ \pm} \pm t_{95} S \text {. }
$$

The value of $t_{95}$ is a function of the number of degrees of freedom used in obtaining $S$. As mentioned previously, when the degrees of freedom of a certain measurement is higher than 30 , $t_{95}$ can be generally taken as $2 .^{9)}$ Values for $t_{95}$ can be found in tables for t-Student's distribution ${ }^{12)}$ as a function of the degrees of freedom of the sample, calculated as follows: ${ }^{11)}$

$$
v=\frac{\left(\sum_{i=1}^{N} S_{i}^{2}\right)^{2}}{\sum_{i=1}^{N} \frac{S_{i}^{4}}{v_{i}}}
$$


where $S_{i}$ is the spread or precision index resulting from the combination of the various error sources, and $v_{i}$ represents the degrees of freedom connected to each error source.

\subsection{Total uncertainty of a measurement}

The error in the measurement of a given parameter involved in the calculation of a final quantity can be propagated by use of influence coefficients describing the effect of a unit error in the parameter on the final result. If $P_{i}$ represents the $i^{t h}$ parameter to be measured in order to obtain a quantity $q$, then the influence coefficients are given by:

$$
\theta_{i}=\frac{\partial q}{\partial P_{i}}
$$

Therefore, the precision of a given quantity $S_{q}$ becomes

$$
S_{q}=\sqrt{\sum_{i=1}^{N}\left(\theta_{i} S_{P_{i}}\right)^{2}}
$$

and for the bias sources:

$$
B_{q}=\sqrt{\sum_{i=1}^{N}\left(\theta_{i} B_{P_{i}}\right)^{2}} .
$$

To apply Eqs. (24) and (25) the uncertainties in the parameters $P_{i}$ must be independent and random, ${ }^{12)}$ using Eq. (21) in the last step to obtain the total uncertainty of a result.

As described in Section 4.1, the effects of mixing and vaporization need to be isolated, in order to discern the level of excellence of a given injector design. In order to accomplish this isolation, all other effects must be accurately estimated. However, the test data and the correction factors have uncertainties associated with them, resulting in an uncertainty in the isolated effect. The model used in calculating this corresponding uncertainty is:

$$
U_{\eta_{C^{*}}}^{ \pm}= \pm t_{95} \sqrt{S_{C_{e x p}^{*}}^{2}+S_{C_{F R}^{*}}^{2}+S_{C_{D I V}^{*}}^{2}+S_{C_{H L}^{*}}^{2}+S_{C_{\text {theo }}^{*}}^{2}} .
$$

Each $S$ factor in Eq. (26) represents the change in injector efficiency caused by a change of magnitude $S$ in the specific factor, as described by Eq. (24).

\subsection{Determination of influence coefficients}

The computation of influence coefficients are required to propagate the errors of measured parameters associated with a final quantity. For analytical expressions, such as those given by Eq. (11), the influence coefficients are obtained by partial differentiation with respect to the parameter of interest. Whenever thermodynamic properties are involved, a small perturbation around the nominal value was used. All propellant thermodynamic state points were calculated using the REFPROP program $^{13)}$ supplied by the National Institute of Standards and Technology (NIST). Expressions for the influence coefficients and their typical values are summarized in Table 1.

Particularly for the velocity at the venturi throat, it is interesting to describe the influence coefficients in terms of measured

\begin{tabular}{|c|c|c|c|}
\hline \multicolumn{2}{|l|}{ Parameter } & Value & Units \\
\hline \multirow[t]{2}{*}{$p_{t h}$} & $\frac{\partial p_{\text {th }}}{\partial p_{\text {line }}}=1$ & 1 & {$[\mathrm{~Pa} / \mathrm{Pa}]$} \\
\hline & $\frac{\partial p_{t h}}{\partial d p}=-1$ & -1 & {$[\mathrm{~Pa} / \mathrm{Pa}]$} \\
\hline \multirow[t]{2}{*}{$\beta$} & $\frac{\partial \beta}{\partial d_{t h}}=\frac{1}{d_{l i n}}$ & $0.170 \times 10^{0}$ & {$[1 / m]$} \\
\hline & $\frac{\partial \beta}{\partial d_{\text {line }}}=-\frac{d_{\text {th }}}{d_{\text {line }}^{2}}$ & $0.690 \times 10^{-1}$ & {$[1 / m]$} \\
\hline \multirow[t]{5}{*}{$V_{t h}$} & $\frac{\partial V_{\text {th }}}{\partial h_{\text {line }}}=\frac{1}{\sqrt{2} \sqrt{\frac{h_{\text {line }}-h_{\text {th }}}{\rho_{t h}}}}$ & $0.590 \times 10^{-1}$ & {$[s / m]$} \\
\hline & $\frac{\partial V_{\text {th }}}{\partial h_{t h}}=-\frac{\partial V_{\text {line }}}{\partial h_{\text {line }}}$ & $0.590 \times 10^{-1}$ & {$[\mathrm{~s} / \mathrm{m}]$} \\
\hline & $\frac{\partial \beta}{\partial d_{\text {line }}}=-\frac{d_{\text {the }}}{d_{\text {line }}^{2}}$ & $0.258 \times 10^{-1}$ & {$[\mathrm{~m} / \mathrm{s}]$} \\
\hline & $\frac{\partial V_{\text {th }}}{\partial \rho_{\text {line }}}=-\frac{\rho_{\text {th }}^{2}}{\rho_{\text {line }}^{3}} \frac{V t \text { th } \beta^{4}}{\left[1-\left(\frac{\rho_{\text {th }}}{\rho_{\text {line }}}\right)^{2} \beta^{4}\right]}$ & $-0.190 \times 10^{-2}$ & {$\left[\mathrm{~m}^{4} / \mathrm{kg} \cdot \mathrm{s}\right]$} \\
\hline & $\frac{\partial V_{\text {th }}}{\partial \rho_{\text {th }}}=\frac{\rho_{\text {th }}}{\rho_{\text {line }}^{2}} \frac{V \text { th } \beta^{4}}{\left[1-\left(\frac{\rho_{t h}}{\rho_{\text {line }}}\right)^{2} \beta^{4}\right]}$ & $0.190 \times 10^{-2}$ & {$\left[m^{4} / k g \cdot s\right]$} \\
\hline \multirow[t]{4}{*}{$\begin{array}{l}\dot{m}_{o} \\
\dot{m}_{f}\end{array}$} & $\frac{\partial \dot{m}}{p_{\text {line }}}=\frac{\partial \dot{m}}{\partial V_{\text {th }}} \frac{\partial V_{\text {th }}}{\partial p_{\text {line }}}+\frac{\partial \dot{m}}{\partial \rho_{\text {th }}} \frac{\partial \rho_{\text {th }}}{\partial p_{\text {line }}}$ & $0.410 \times 10^{-9}$ & {$\left[m^{3} \cdot s / k g^{2}\right]$} \\
\hline & $\frac{\partial \dot{m}}{\Gamma_{\text {line }}}=\frac{\partial \dot{m}}{\partial V_{\text {th }}} \frac{\partial V_{\text {th }}}{\partial T_{\text {line }}}+\frac{\partial \dot{m}}{\partial \rho_{\text {th }}} \frac{\partial \rho_{\text {th }}}{\partial T_{\text {line }}}$ & $-0.170 \times 10^{-3}$ & {$[\mathrm{~kg} \cdot \mathrm{s} / \mathrm{K}]$} \\
\hline & $\frac{\partial \dot{m}}{\partial d p}=\frac{\partial \dot{m}}{\partial V_{t h}} \frac{\partial V_{t h}}{\partial d p}+\frac{\partial \dot{m}}{\partial \rho_{t h}} \frac{\partial \rho_{t h}}{\partial d p}$ & $0.280 \times 10^{-6}$ & {$[s / m]$} \\
\hline & $\frac{\partial \dot{m}}{\partial d_{\text {line }}}=\frac{\partial \dot{m}}{\partial V_{\text {th }}} \frac{\partial V_{\text {th }}}{\partial d_{\text {line }}}$ & $-0.230 \times 10^{0}$ & {$[\mathrm{~kg} / \mathrm{s} \cdot \mathrm{m}]$} \\
\hline \multirow[t]{2}{*}{$\dot{m}_{t}$} & $\frac{\partial \dot{m}_{t}}{\partial \dot{m}_{o}}=1$ & 1 & {$\left[\mathrm{kgs}^{-1} / \mathrm{kg} \cdot \mathrm{s}^{-1}\right.$} \\
\hline & $\frac{\partial \dot{m}_{t}}{\partial \dot{m}_{f}}=1$ & 1 & {$\left[k g s^{-1} / k g \cdot s^{-1}\right.$} \\
\hline \multirow[t]{3}{*}{$C_{e x p}^{*}$} & $\frac{\partial C_{e x p}^{*}}{\partial p_{k}}=\frac{f_{p} A_{t} f_{T R}}{\dot{m}_{t}}$ & $0.240 \times 10^{-3}$ & {$\left[m^{2} \cdot s / k g\right]$} \\
\hline & $\frac{\partial C_{e x p}^{*}}{\partial A_{t}^{*}}=\frac{p_{k} f_{p} f_{T R}}{\dot{m}_{t}}$ & $0.205 \times 10^{6}$ & {$[1 / s]$} \\
\hline & $\frac{\partial C_{e x p}^{*}}{\partial \dot{m}_{t}}=-\frac{p_{k} f_{p} A_{t} f_{T R}}{\dot{m}_{t}^{2}}$ & $-0.190 \times 10^{5}$ & {$\left[{ }^{m} / k g\right]$} \\
\hline
\end{tabular}
parameters, i.e. pressure and temperature in the line and pressure drop across the venturi. If $\kappa$ is a calculated thermodynamic
Table 1. Influence coefficients.

property (either enthalpy, temperature or density at the venturi throat), then the chain rule applies:

$$
\begin{aligned}
\frac{\partial \kappa}{\partial p_{\text {line }}} & =\frac{\partial \kappa}{\partial p_{\text {th }}} \frac{\partial p_{\text {th }}}{\partial p_{\text {line }}}+\frac{\partial \kappa}{\partial s_{\text {line }}} \frac{\partial s_{\text {line }}}{\partial p_{\text {line }}} \\
\frac{\partial \kappa}{\partial \Delta_{p}} & =\frac{\partial \kappa}{\partial p_{\text {th }}} \frac{\partial p_{\text {th }}}{\partial \Delta_{p}} \\
\frac{\partial \kappa}{\partial T_{\text {line }}} & =\frac{\partial \kappa}{\partial s_{\text {line }}} \frac{\partial s_{\text {line }}}{\partial T_{\text {line }}} .
\end{aligned}
$$

Eq. (21) and Eq. (24) through Eq. (29) plus expressions in Table 1 form the basis for the calculation of all uncertainties.

\subsection{Error sources}

Possible error sources associated with each instrument was carefully traced for calibration and data acquisition errors. In the case of pressure tranducers, hysteresis and non-linearity were calibrated out using a precision electronic calibrator as reference. Sources of data acquisition errors originated from pressure sensor temperature variations during data collection and zero shift were mitigated by effecting the calibration at test conditions.

The venturi meters were periodically calibrated using water against high precision magnetic inductive type flowmeters. Discrepancies in the values of discharge coefficients obtained with water and the real, low viscosity propellants, were acknowledged. Unfortunately, no other means were available at the time of testing to assess discharge coefficient values associated with the real propellants.

Thermocouples used in the feed-system lines and combustion chamber were not calibrated; these were employed as per supplier stated precision standards. In the case of the combustion 
chamber, several sources of error influence the values of transient temperature. Some of these errors include disturbances in thermocouple reading due to roughness in combustion and chamber operation, uncertainty of the exact location of a innerwall thermocouple and of the thermal properties of the combustion chamber wall material.

Thrust measurement errors due to a shift in load cell output signal caused by rigid propellant lines, valve connections and flexures were verified and compensated for prior to engine testing. Offset reading error was eliminated since the load cell was zeroed prior to each test fire. Errors due to misalignment between thrust chamber force vector and the resultant component measured by the load cell, as well as those resulting from misalignment of forces acting on an axis different from the engine centerline could not be entirely quantified and eliminated.

Errors due to data reduction techniques included, for example, the effect of smoothing and linear interpolation of recorded propellant and chamber temperatures or calculated thermal properties. In the case of propellant flow rate computation, errors are inevitably present if two-phase flow develops in the line. Whenever two-phase flow upstream of the venturi exists, only such thermodynamic properties as pressure and temperature are not sufficient to characterize the flow and knowledge of the vapour quality is needed. ${ }^{14)}$ Figure 6 presents typical signal traces obtained during an early test for both venturi meters. Pressure oscilations in the $\mathrm{LO}_{2}$ venturi meter indicate twophase flow was present. Appropriate venting of the lines and permanent liquid nitrogen cooling flow through the venturi meter jackets was conducted prior to and during data taking in order to maintain propellants in subcooled conditions. Additionally, values of mass flow converted from orifices mounted downstream of the main valves served as backup to the venturi meters. Values from venturi and orifice flow meters agreed to within $\pm 4 \%$ of one another. Figure 5 shows a break down of all contributing scattered errors associated with $\mathrm{LCH}_{4}$ flow rate. A big portion of the total error is attributed to venturi discharge coefficient and pressure drop. These results are somewhat inflated by worst-case instrumentation and data acquisition errors assumed in the analysis, but certainly demonstrate areas of improvement.

\section{Results}

Preliminary tests employed two different $\mathrm{LO}_{2}$ orifice shapes and a reduced chamber contraction ratio of 9 . The injector was water-flow calibrated prior to engine tests in order to establish basic hydraulic characteristics and to set the proper shim thickness for the $\mathrm{LCH}_{4}$ injector, as shown qualitatively in Fig. 7a and Fig. 7b.

Figure 8 depicts typical pressure traces and Fig. 9 illustrates the general aspect of the exhaust flame in a test-run. The calculation of characteristic exhaust velocity followed by the chamber pressure method and the $C^{*}$ efficiency was calculated as indicated in Subsection 4.1.1. Initially, no corrections were made for engine friction losses, throat area change or heat losses to the chamber wall. The final precision in $\eta_{C *}$ was $\pm 4.5 \%$ for one standard deviation.

The slot-shaped (rectangular) orifice, was the first configuration tested (Injector 1). The proposed arrangement uses a single

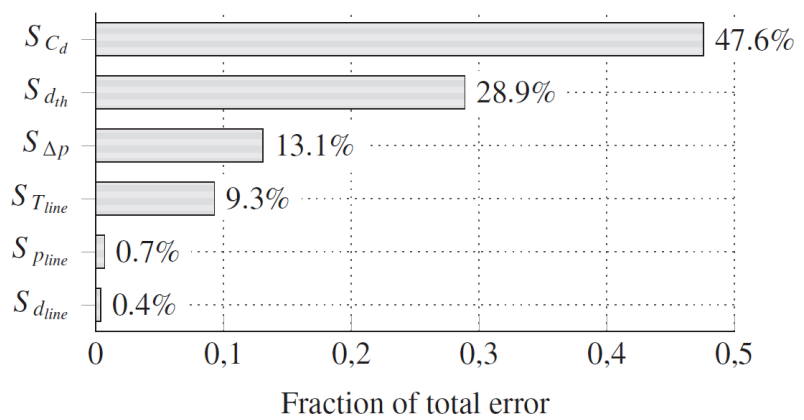

Fig. 5. Breakdown of scattered errors in $\mathrm{LCH}_{4}$ mass flow rate.

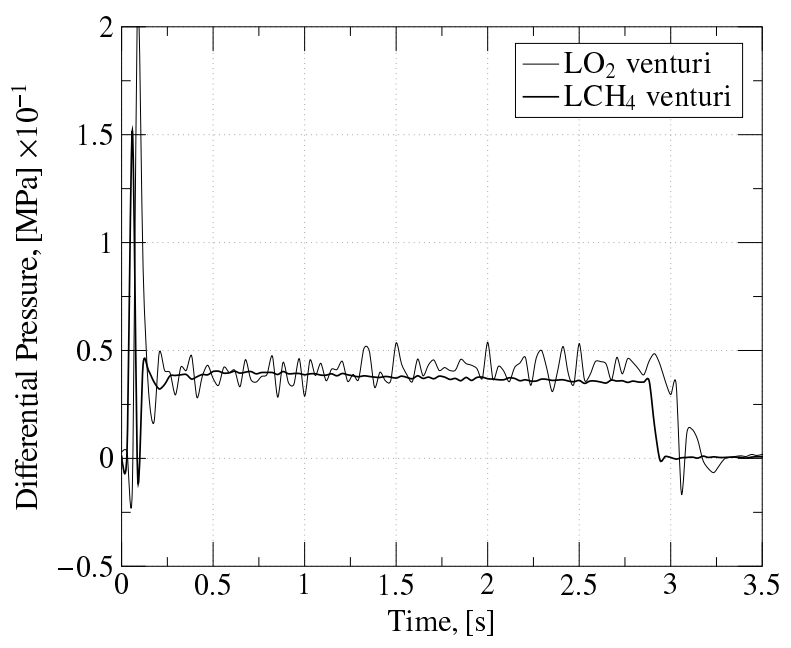

Fig. 6. Representative pressure traces for the venturi meters.

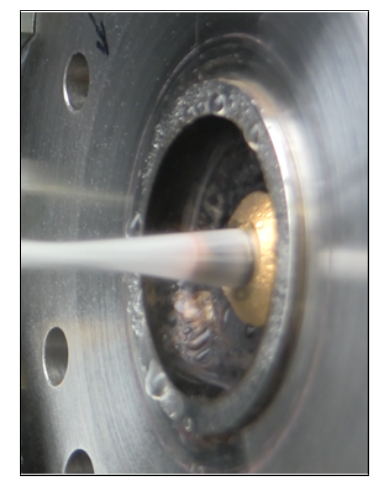

(a) $\mathrm{LCH}_{4}$ injector flow employ- 1 ing a $2-[\mathrm{mm}]$ thick shim.

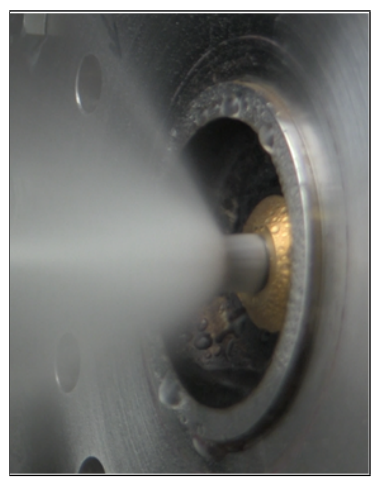

(b) $\mathrm{LO}_{2}$ and $\mathrm{LCH}_{4}$ flows at optimum momentum balance.
Fig. 7. Injector cold-flow testing.

row of twelve orifices as shown in Fig. 10.

Similar to the slot geometry, twelve orifices were used with the circular orifice geometry (Injector 2). In comparison to the slot shape, circular orifices showed better flow reproducibility during water calibration and a wider spray angle. At such dimensions, they also offer advantages in terms of manufacturing. For these reasons, these tests aimed at answering the question: what can a slot geometry accomplish that cannot be accomplished by a circular geometry? Performance computation for both injector configurations is shown in Fig. 11. In fact, there is no discernible performance difference in terms of combustion efficiency within the given error between both configurations at the design point. The value around $\eta_{C^{*}}=90.5 \%$ at the design $K_{m}$ 


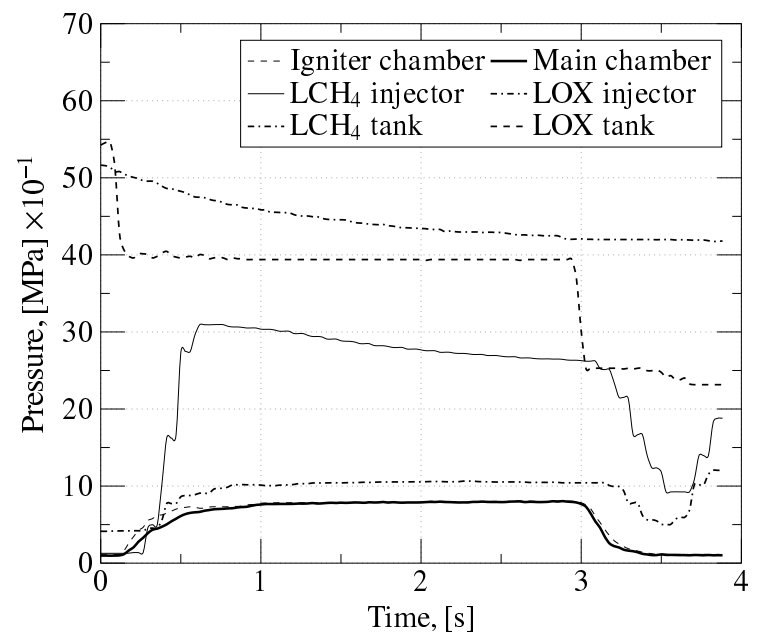

Fig. 8. Representative pressure traces.

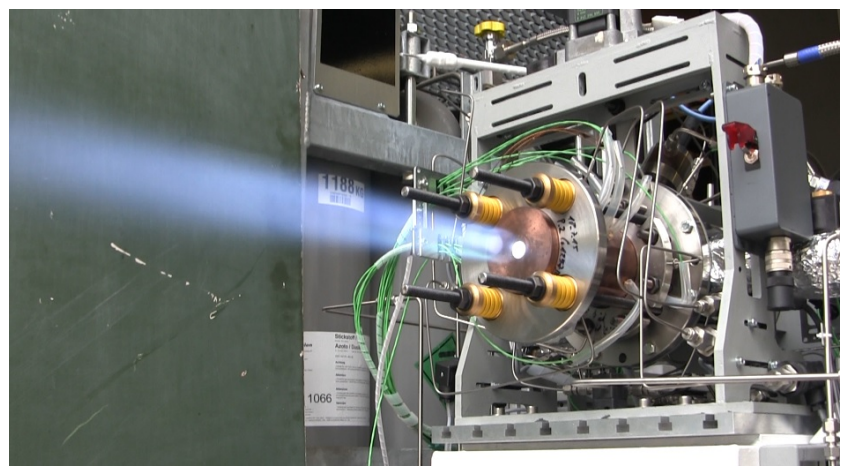

Fig. 9. Typical hot-fire test run.

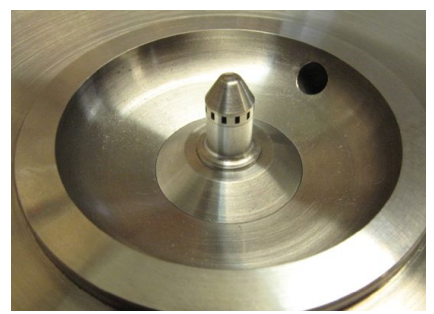

Fig. 10. Slot orifices mounted to the pintle tip.

of 2.8 for the slot shape was satisfactory. This compares with an $\eta_{C^{*}}=89.0 \%$ for the round $\mathrm{LO}_{2}$ orifices. However, the circular shape exhibited lower performance decay across the mixture ratios tested. This is because of the constant momentum ratio obtained in these tests and probably some improvement in mixing as a consequence of increased residence time resulting from the wider spray angle.

A second series of tests employed two slightly modified versions of the injector (Injector 3 and Injector 4) in an attempt to reduce thermal loads to the pintle tip and nozzle throat. In this case, an uncooled nozzle with an expansion area ratio of $4: 1$ and a chamber characteristic length of $1.45[\mathrm{~m}]$ and nominal contraction ratio of 13 was used. Corrected values for the characteristic velocity efficiency were computed by both methods presented in Subsections 4.1.1 and 4.1.2. Figure 12 gives the calculated combustion efficiency as a function of mixture ratio an the comparison of both methods of $\eta_{C^{*}}$ computation. Calculations based on both techniques agree to within $\pm 2.5 \%$ of one another. This is somehow an optimistic figure, since
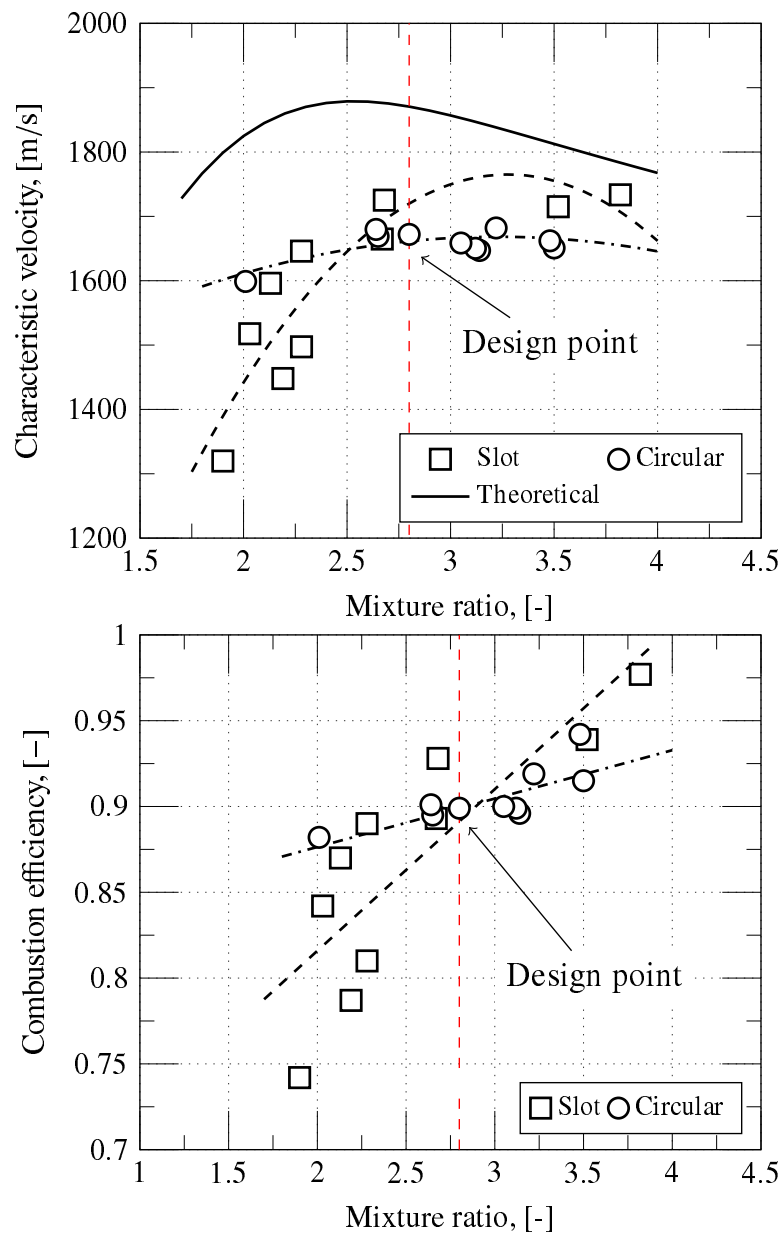

Fig. 11. Computed performance comparison for the slot and circular orifices.

thrust cell bias errors could not be fully eliminated or identified. Injector 4 has slightly better performance than Injector 3 at the same mixture ratio. With the errors considered, both injectors were around $80 \%$ efficient at the design point. The lower performance in comparison with the previously tested injectors are believed to result from design modifications leading to $\mathrm{LCH}_{4}$ flow momentum losses and poorer interaction with the $\mathrm{LO}_{2}$ sprays. A summary of injector performance and operating conditions is given in Table 2.

Table 2. Performance summary for the evaluated injectors ( $K_{m}=2.8[-], p_{k}=1.0[\mathrm{MPa}]$ abs., chamber pressure method).

\begin{tabular}{cccccc}
\hline & \multicolumn{2}{c}{$\Delta p_{\text {inj }}[\mathrm{MPa}]$} & & & \\
\cline { 2 - 3 } Injector & $\mathrm{LO}_{2}$ & $\mathrm{LCH}_{4}$ & $\eta_{C^{*}},[\%]$ & $L^{*},[\mathrm{~m}]$ & $\epsilon_{k},[-]$ \\
\hline 1 & 0.024 & 2.10 & 90.5 & 2.40 & 9 \\
2 & 0.026 & 2.14 & 89.0 & 2.40 & 9 \\
3 & 0.029 & 0.49 & 78.8 & 1.45 & 13 \\
4 & 0.011 & 0.95 & 83.9 & 1.45 & 13 \\
\hline
\end{tabular}

\section{Conclusion}

A methodology has been developed for the determination of uncertainty in the final calculated values of characteristic com- 

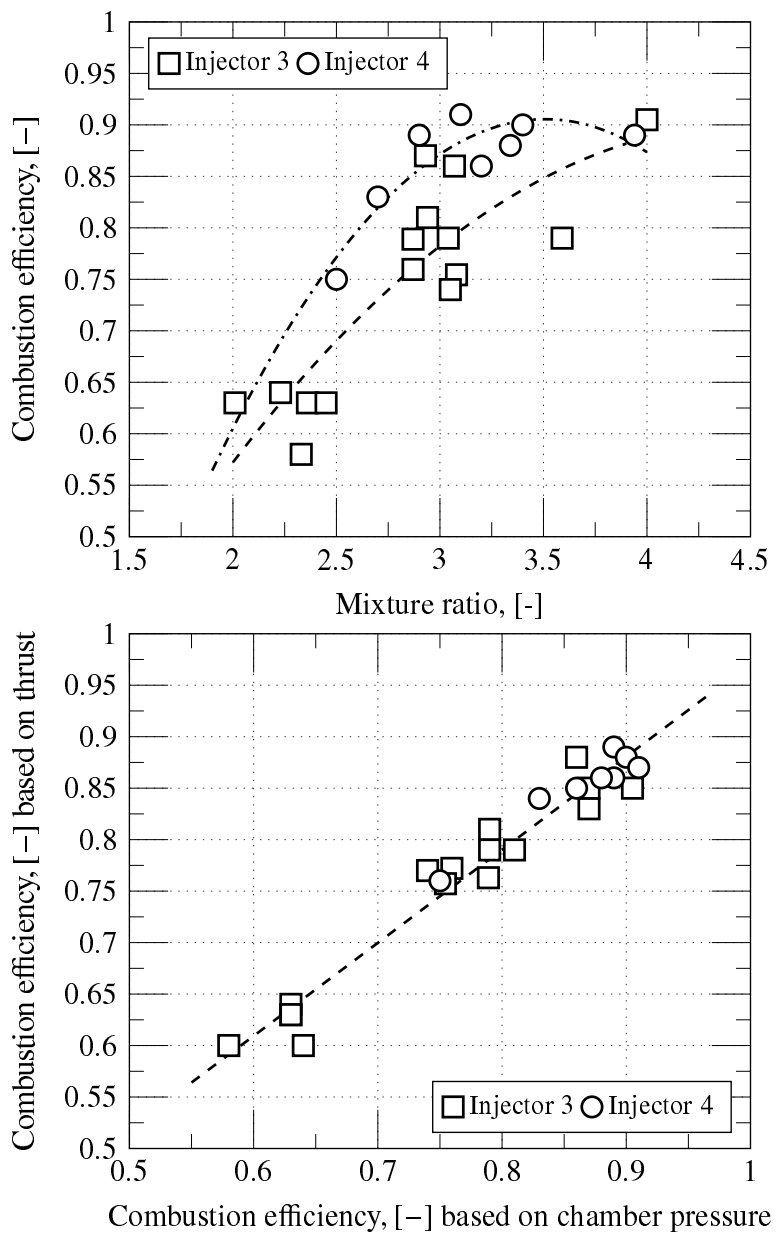

Fig. 12. Performance comparison for injectors 3 and 4 and correlation between both methods of $\eta_{C^{*}}$ computation.

bustion efficiency for a pintle injector operating with cryogenic $\mathrm{LO}_{2}$ and $\mathrm{LCH}_{4}$ propellants and an uncooled combustion chamber. Uncertainty is given by a bias and a precision, which is computed after the propagation of system elemental errors. Two techniques for $\eta_{C^{*}}$ computation were presented, one based on chamber pressure and another on thrust measurements.

Critical factors affecting the accuracy of the experimentally determined characteristic velocity are: (1) the accuracy of the knowledge of the propellant thermodynamic properties ustream of venturi inlet; (2) the deviation in venturi discharge coefficient calibrated with water with respect to real propellants and the accuracy of this calibration; (3) the accuracy of thrust measurements, due to unknown bias errors.

Tests have been made with four pintle injector configurations. Injectors 1 and 2 performed closely, and within the error margin of $\pm 4.5 \%$ in $\eta_{C^{*}}$ no conclusion can be stated in terms of performance advantages of one injector configuration over the other. Tests made with two additional pintle injector configurations gave combustion efficiency values in terms of independent thrust and chamber pressure measurements which agreed to within $\pm 2.5 \%$ of one another. The accuracy of the determination will depend on the correct estimation of propellant thermodynamic state and on the degree of refinement of experimental techniques as well as in the accuracy with which the data for experimental characteristic velocity correction are obtained.

\section{Acknowledgments}

The authors would like to thank Capes (Nr. 9337/2013) for their suppport in the development of this work.

\section{References}

1) Schoenman, L.: Low-thrust ISP Sensitivity Study, Aerojet Liquid Rocket Company, NASA CR-165621, 1982.

2) Casiano, M. J., Hulka, J. R., and Yang, V.: Liquid-Propellant Rocket Engine Throttling: A Comprehensive Review, J. of Propulsion and Power, 5(2010), pp.897-923.

3) Harrje, T. D.: Liquid Propellant Rocket Combustion Instability, NASA SP-194, Cleveland, Ohio, 1972.

4) Bazarov, V. G.: Throttleable Liquid Propellant Engines Swirl Injectors for Deep Smooth Thrust Variations, AIAA Paper 94-2978, 1994

5) Hammock, R. W., Currie, C. E., and Fisher, E. A.: Apollo Experience Report - Descent Propulsion System, NASA TN D-7143, 1973.

6) Dressler, G. A.: Summary of Deep Throttling Rocket Engines with Emphasis on Apollo LMDE, AIAA Paper 2006-5220, 2006.

7) Popp, M., Hulka, J., Yang, V., and Habiballah, M.: "Liquid Bipropellant Injectors", Liquid Rocket Thrust Chambers: Aspects of Modeling, Analysis and Design, Progress in Astronautics and Aeronautics, Washington, D.C., 200(2004), pp.141-165.

8) Sutton, G. P. and Biblarz, O.: Rocket Propulsion Elements, John Wiley \& Sons Inc., Hoboken, New Jersey, 2010, pp.282-283.

9) Gross, K. W. and Evans, S. A.: JANNAF Rocket Engine Performance Test Data Acquisition and Interpretation Manual, CPIA Publication $245,1975$.

10) Abernethy, R. B. and Thompson, J. W.: Handbook, Uncertainty in Gas Turbine Measurements, Arnold Air Force Station, Tennessee, AEDC-TR-73-5, 1973.

11) Kenneth, J. D.: Pretest Uncertainty Analysis for Chemical Rocket Engine Tests, NASA-TM-89819, 1987.

12) Taylor, R. J.: An Introduction to Error Analysis, University Science Books, Sausalito, 1997, pp.121-153.

13) Lemmon, E. W., Huber, M. L., and McLinden, M. O.: NIST Standard Reference Database 23: Reference Fluid Thermodynamic and Transport Properties-REFPROP, Version 9.1, National Institute of Standards and Technology, Standard Reference Data Program, Gaithersburg, 2013.

14) Filippov, Yu. P. and Panferov, K. S.: Two-Phase Cryogenic Flow Meters, Part II - How to Realize the Two-Phase Pressure Drop Method, Cryogenics, 51(2011), pp.640-645. 